\title{
Transcriptomic analysis of the trade-off between endurance and burst-performance in the frog Xenopus allofraseri
}

Valérie Ducret ${ }^{1 *}$ (D), Adam J. Richards², Mathieu Videlier ${ }^{3}$, Thibault Scalvenzi ${ }^{4}$, Karen A. Moore ${ }^{5}$, Konrad Paszkiewicz ${ }^{5}$, Camille Bonneaud ${ }^{2,6}$, Nicolas Pollet ${ }^{4}$ and Anthony Herrel ${ }^{2,7}$

\begin{abstract}
Background: Variation in locomotor capacity among animals often reflects adaptations to different environments. Despite evidence that physical performance is heritable, the molecular basis of locomotor performance and performance trade-offs remains poorly understood. In this study we identify the genes, signaling pathways, and regulatory processes possibly responsible for the trade-off between burst performance and endurance observed in Xenopus allofraseri, using a transcriptomic approach.

Results: We obtained a total of about 121 million paired-end reads from Illumina RNA sequencing and analyzed 218,541 transcripts obtained from a de novo assembly. We identified 109 transcripts with a significant differential expression between endurant and burst performant individuals (FDR $\leq 0.05$ and $\log F C \geq 2$ ), and blast searches resulted in 103 protein-coding genes. We found major differences between endurant and burst-performant individuals in the expression of genes involved in the polymerization and ATPase activity of actin filaments, cellular trafficking, proteoglycans and extracellular proteins secreted, lipid metabolism, mitochondrial activity and regulators of signaling cascades. Remarkably, we revealed transcript isoforms of key genes with functions in metabolism, apoptosis, nuclear export and as a transcriptional corepressor, expressed in either burst-performant or endurant individuals. Lastly, we find two up-regulated transcripts in burst-performant individuals that correspond to the expression of myosin-binding protein C fast-type (mybpc2). This suggests the presence of mybpc2 homoeologs and may have been favored by selection to permit fast and powerful locomotion.
\end{abstract}

Conclusion: These results suggest that the differential expression of genes belonging to the pathways of calcium signaling, endoplasmic reticulum stress responses and striated muscle contraction, in addition to the use of alternative splicing and effectors of cellular activity underlie locomotor performance trade-offs. Ultimately, our transcriptomic analysis offers new perspectives for future analyses of the role of single nucleotide variants, homoeology and alternative splicing in the evolution of locomotor performance trade-offs.

Keywords: Anura, Limb, Muscle, Myosin, RNA-sequencing, Stamina

\footnotetext{
* Correspondence: Valerie.ducret@gmail.com

'UMR 7179 MECADEV, C.N.R.S/M.N.H.N., Département Adaptations du Vivant,

55 Rue Buffon, 75005 Paris, France

Full list of author information is available at the end of the article
}

(c) The Author(s). 2021 Open Access This article is licensed under a Creative Commons Attribution 4.0 International License, which permits use, sharing, adaptation, distribution and reproduction in any medium or format, as long as you give appropriate credit to the original author(s) and the source, provide a link to the Creative Commons licence, and indicate if changes were made. The images or other third party material in this article are included in the article's Creative Commons licence, unless indicated otherwise in a credit line to the material. If material is not included in the article's Creative Commons licence and your intended use is not permitted by statutory regulation or exceeds the permitted use, you will need to obtain permission directly from the copyright holder. To view a copy of this licence, visit http://creativecommons.org/licenses/by/4.0/. The Creative Commons Public Domain Dedication waiver (http://creativecommons.org/publicdomain/zero/1.0/) applies to the data made available in this article, unless otherwise stated in a credit line to the data. 


\section{Background}

Locomotor performance has a strong impact on the survival and reproduction of many organisms [1-3]. Burst performance is often most relevant in the context of prey capture and predator escape, whereas endurance is relevant in the context of territory defense, dispersal, or migration. Yet, the evolution of locomotor performance can be constrained if performance traits are involved in traded-offs, as often observed between burst performance and endurance capacity in vertebrates [4-9]. Conflicting demands on muscles to express either fast-twitch glycolytic fibers that facilitate burst performance or slow-twitch oxidative muscle fibers that enhance stamina may explain in part this performance trade-off [10-13]. Although the physiological basis of this performance trade-off has been documented, how it is governed at the gene expression level remains poorly understood. Uncovering the molecular basis and biological pathways underlying performance trade-offs is therefore essential for understanding the adaptive evolution of these traits.

Because locomotor performance is heritable [14-16], efforts have been made to explain differences in physical performance by variation in coding DNA in humans [17-19], racing pigeons [20], mice [21], horses [22] and dogs [23]. While those studies highlighted a remarkable number of genetic variants associated with variation in physical performance, they provide little insight into the potential processes underlying performance trade-offs. Altogether, the myriad of genetic variants with little phenotypic effects has led to the consensus that physical performance is a polygenic trait that is governed by features such as transcriptional regulation. Recently, microRNAs have been found to regulate the expression of target genes in skeletal muscle [24, 25], as well as target genes involved in muscle cell proliferation, differentiation, motility and regeneration [26]. In humans, a transcriptional map established after endurance exercise training highlighted an important regulation of gene expression to increase aerobic capacity [27]. Although a few transcriptomic analyses have been performed in the context of physical performance [20, 27, 28], none have tried to understand the factors underlying performance trade-offs.

In this study, we analyzed the transcriptomes of eight adult Xenopus allofraseri males from a single population that show a marked trade-off between endurance and burst-performance capacity. We performed a RNA-seq analysis of genes expressed in limb muscle that allowed us to highlight the genes, signaling pathways, and regulatory processes such as alternative splicing likely underlying this locomotor performance trade-off.

\section{Results and discussion}

Raw sequencing data, de novo assembly and quality control

We obtained a total of about 121 million paired-end reads using Illumina RNA sequencing. After trimming and quality filtering, biological replicates produced between 5.2 and 28 million paired-end reads (Table 1). The number of reads in each group was well balanced with 5.5 million in the endurant group and 6.6 million in the burst-performant group. The BUSCO analysis resulted in $65.4 \%$ gene identification $(54.9 \%$ completeness and $10.5 \%$ of fragmented genes), which is relatively good as only one muscle tissue was sampled. Next, we evaluated the Trinity de novo assemblies by mapping the trimmed reads. We obtained an overall alignment rate of $>97 \%$ percent identity and $>89 \%$ of reads aligned as proper pairs (Table 1 ). The de novo assembly consisted of 218,541 transcripts and 163,981 'genes' with an E90N50 value (i.e. the N50 for transcripts that represent $90 \%$ of the total normalized expression data) of $1462 \mathrm{pb}$. These different metrics testify that our transcriptome assemblies were of good quality.

\section{Physical performance}

Transcript levels were quantified with respect to endurant and burst performant classifications after measuring four physical performance traits: maximum distance jumped before exhaustion $(\mathrm{m})$, maximum time jumped before exhaustion (s), maximum burst velocity $\left(\mathrm{m} . \mathrm{s}^{-1}\right)$, and maximum burst acceleration $\left(\mathrm{m} . \mathrm{s}^{-2}\right)$ (Table 2). The

Table 1 Summary of quality scores for the sequencing of the eight males Xenopus allofraseri (named sample A to H)

\begin{tabular}{lllll}
\hline Sample & Paired-end reads & Total singleton reads & $>=$ Q30 (\%) & Mean quality score \\
\hline A & $8,961,655$ & $17,923,310$ & 94.02 & 36.42 \\
B & $16,672,325$ & $33,344,650$ & 93.97 & 36.41 \\
C & $28,509,462$ & $57,018,924$ & 93.71 & 36.31 \\
D & $14,145,979$ & $28,291,958$ & 94.07 & 36.44 \\
E & $20,664,890$ & $41,329,780$ & 94.19 & 36.49 \\
F & $15,697,497$ & $31,394,994$ & 94.06 & 36.44 \\
G & $11,647,327$ & $23,294,654$ & 36.54 & 36.41 \\
H & $5,288,288$ & $10,576,576$ & 94.00 & \\
\hline
\end{tabular}

Q30: Phred quality scores when probability of incorrect base call is 1 in 1000 
Table 2 Individual measures of locomotor performance of the eight males Xenopus allofraseri (named sample A to H)

\begin{tabular}{llllll}
\hline Sample & Category & Velocity $\left(\mathbf{m} . \mathbf{s}^{-\mathbf{1}}\right)$ & Acceleration $\left(\mathbf{m . s}^{\mathbf{- 2}}\right)$ & Time $(\mathbf{s})$ & Distance $(\mathbf{m})$ \\
\hline A & Endurant & 1.17 & 54.41 & 71 & 1.190 \\
B & Burst-performant & 1.67 & 47.75 & 46 & 0.530 \\
C & Burst-performant & 1.87 & 61.83 & 36 & 0.590 \\
D & Endurant & 1.10 & 45.17 & 55 & 0.840 \\
E & Endurant & 1.20 & 43.80 & 96 & 1.310 \\
F & Burst-performant & 1.87 & 49.69 & 54 & 0.575 \\
G & Endurant & 1.56 & 46.05 & 73 & 1.040 \\
H & Burst-performant & 1.44 & 48.42 & 32 & 0.560 \\
\hline
\end{tabular}

principal component analysis (PCA) followed by the agglomerative hierarchical clustering allowed to clearly segregate individuals into the two groups (burst performant vs. endurant individuals; Fig. 1) confirming the existence of a locomotor trade-off in this species. Maximum distance, maximum time and maximum velocity contributed mainly to the first axis of the PCA (respectively 92.1, 90.5 and $81.3 \%$ ), whereas maximum acceleration contributed to the second axis (75.3\%).

\section{Phylogenetic analysis}

Phylogenetic analysis of the mitogenomes indicated that mitochondrial DNA from the eight Хenopus males (Sample A to H, Fig. 2) are closely related and correspond to specimens of the species Xenopus allofraseri.
These mitochondrial sequences are sister to those of Xenopus pygmaeus and markedly diverge from other Xenopus species such as Xenopus laevis and Xenopus tropicalis. Noticeably, the eight Xenopus allofraseri males were captured in a geographic range that was not previously reported for this species [29].

\section{Differentially expressed transcripts}

We identified 109 transcripts with a significant differential expression between endurant and burst performant individuals (Fig. 3). Six of those transcripts yielded no similarities to either the Uniprot or the NCBI databases. The blast searches resulted in 103 protein-coding genes (Table S1) matching either Xenopus laevis $(n=94)$ or Xenopus tropicalis $(n=9)$ proteins. Due to alternative

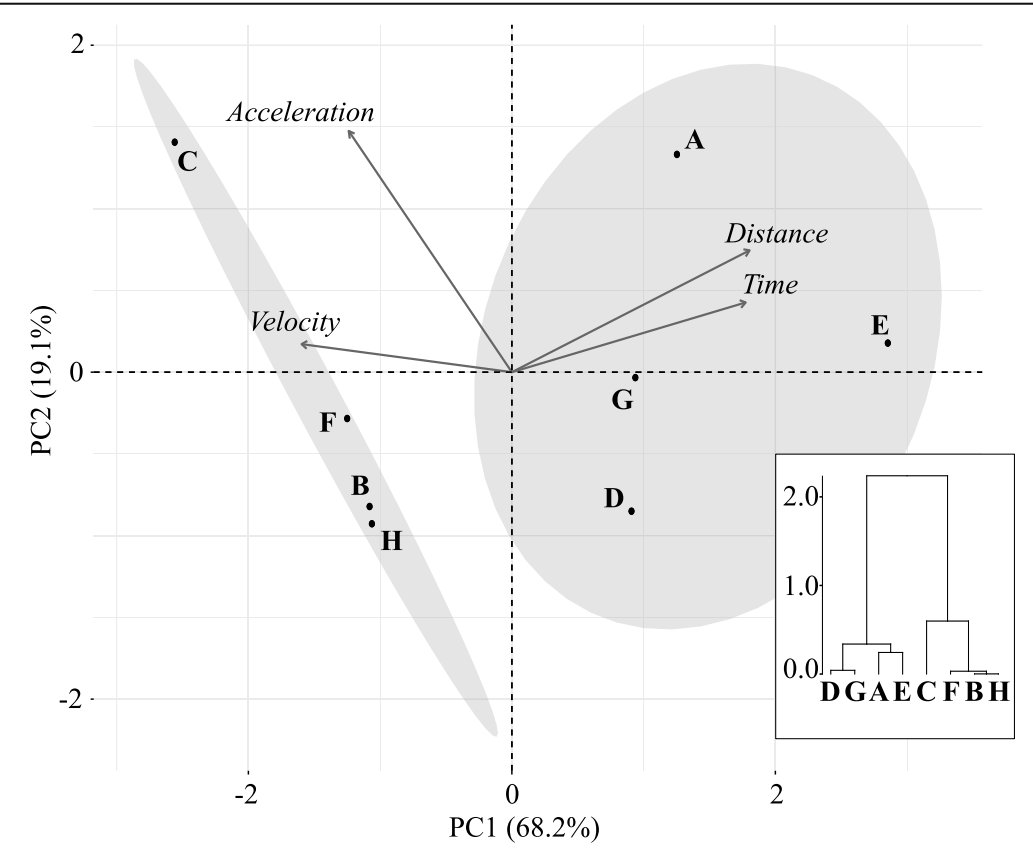

Fig. 1 Principal Component Analysis (PCA) and agglomerative hierarchical clustering of the four locomotor performance traits in eight males Xenopus allofraseri (named sample A to $\mathrm{H}$ ): distance (total distance jumped until exhaustion), time (maximum time spent moving until exhaustion), acceleration (maximal instantaneous acceleration during an escape locomotor burst), velocity (maximal instantaneous speed during an escape locomotor burst) 


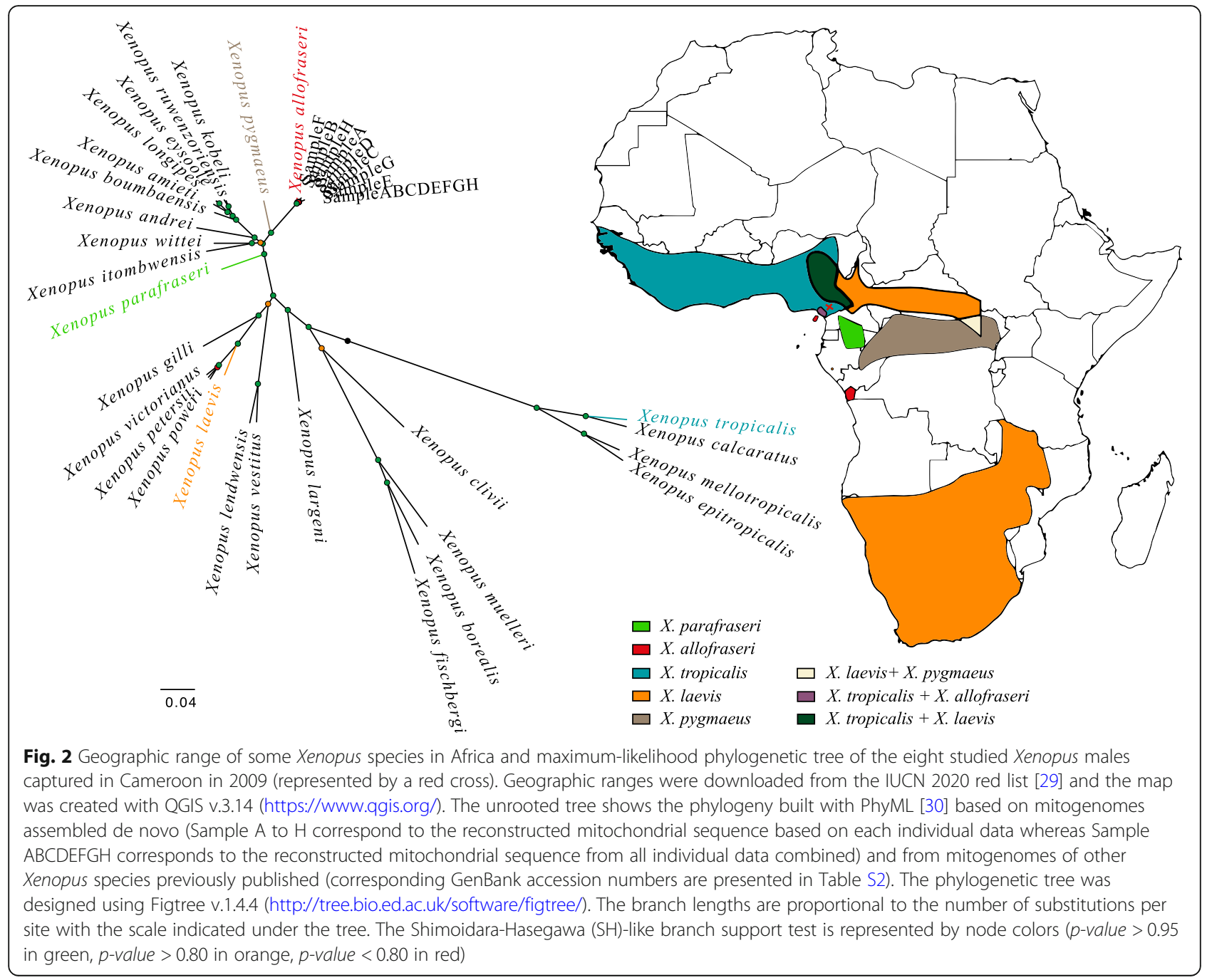

splicing, some transcripts blasted to the same gene, therefore we identified 90 unique protein-coding genes. Using the human STRING database, we generated nine networks involving 46 differentially expressed proteincoding genes (Fig. 4).

We highlighted differentially expressed protein-coding genes involved in the structural organization and functioning of muscle cells, such as actin cytoskeleton and microtubule composition, conformation, mitochondrial activity, and cellular trafficking. Yet, it appears that many of those transcripts have regulatory properties or are effectors of downstream signaling cascades, starting from stimuli in the extracellular matrix and involving cell surface or transmembrane proteins. Consequently, endurant and burst-performant individuals differ in the functional pathways that are initiated by those up-stream effectors.

\section{Transmembrane proteins and focal adhesions}

Focal adhesion are macromolecular assemblies that play key roles in linking the extracellular matrix to the cytoskeleton [33] and act as important signal transducer [34]. In loading muscle, previous study highlighted the role of focal adhesion kinase (FAK, PTK2 gene) to act as a mediator, and transmit a stress and strain signal by integrins (transmembrane receptors) that activate multiple anti-apoptotic, cell growth pathways [35] and increase muscle mass [36]. Whereas FAK lead to slow twitch muscle generation and to an up-regulation of genes involved in mitochondrial metabolism [37], FAKrelated non-kinase (FRNK) - a protein transcribed from the FAT portion of the FAK gene - acts to inhibit FAK in many cell types, including skeletal muscle [38]. In our study, we find $p t k 2$ and other protein-coding genes ( $g c a$, lmo7) involved in focal adhesion and the signal transduction cascade through the activation of Rho-GTPases (e.g. RhoG, rac1, cdc42) to be up-regulated in burstperformant individuals. Also, kinectin 1 (ktn1), a receptor for kinesin that accumulates in integrin-based adhesion complexes, is up-regulated in endurant individuals, whereas mef $2 a$, a DNA-binding transcription factor of 


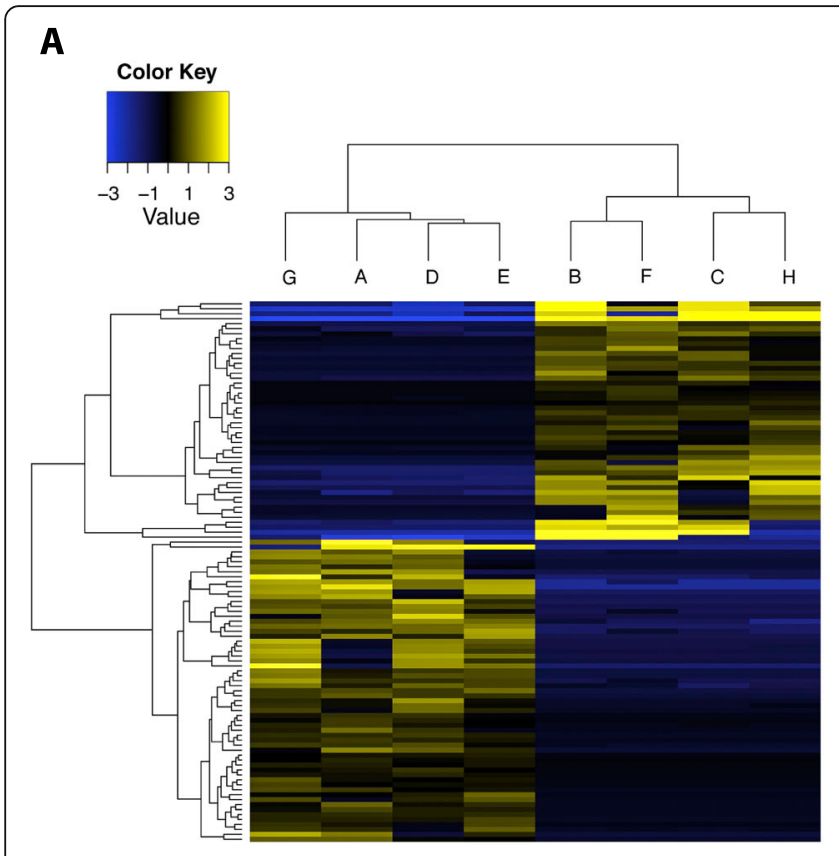

\section{B}

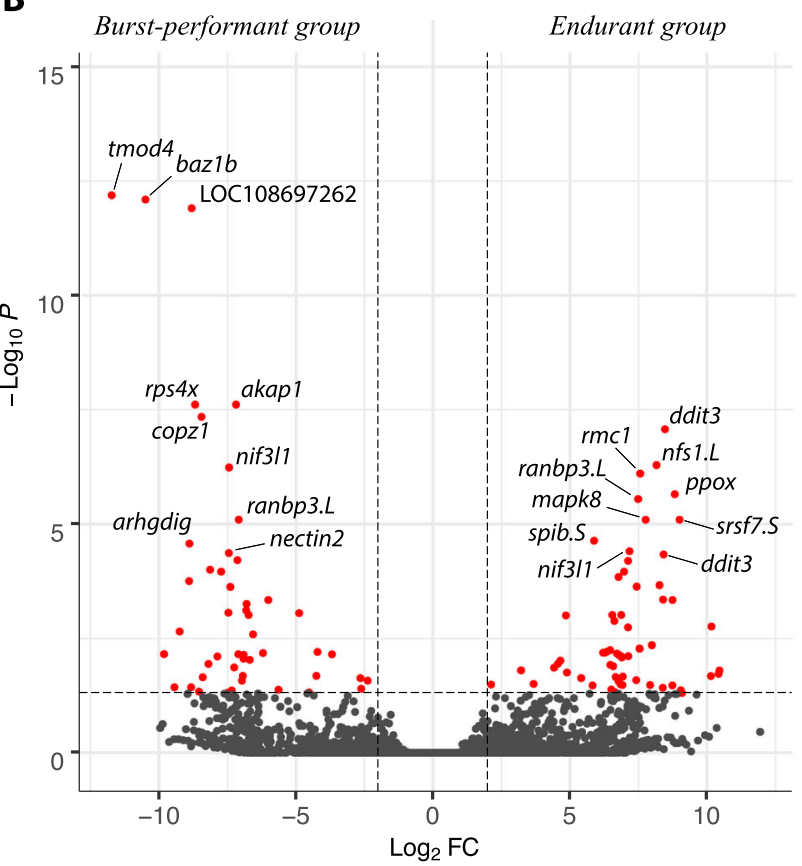

Fig. 3 a Heatmap representation of the regularized log-transformed counts for the de novo assembly. All transcripts $(n=109)$ shown had significance levels with (FDR) $\leq 0.05$. The expression values are plotted in log2 space and mean-centered, and show up-and down-regulated expression as yellow and blue, respectively. $\mathbf{b}$ Volcano plot of all de novo transcripts and the red data points corresponding to the significantly differentially expressed transcripts. Gene symbol of the top 10 most differentially expressed transcripts in endurant and in burst-performant groups are plotted

$k t n 1$, is up-regulated in burst-performant individuals. Remarkably, kinectin interacts with RhoG to activate rac1 and cdc42 through a microtubule-dependent pathway [39]. Indeed, kinesins are major microtubule motor proteins that have different functional properties depending on the 'cargo' (i.e. vesicle) they transport. We found several genes involved in microtubule composition and elongation, such as tubg1 and ckap5, to be upregulated in burst-performant individuals. Those genes interact with a centromere protein R-like (an ortholog of $I T G B 3 B P$ ) that is up-regulated in endurant individuals (Fig. 4).

Furthermore, we found a differential expression of several protein-coding genes related to cellular trafficking and the Golgi apparatus. This central organelle system of the secretory pathway biosynthesizes proteoglycans [40]. It is also an important center for the formation of microtubules for its own functioning, also called 'MTOC' [41]. We found RhoGDI-3 (arhgdig) to be upregulated in burst-performant individuals and it targets RhoG from the Golgi apparatus to be activated locally [42]. Interestingly, arafgap 1, which codes for a GTPaseactivating protein involved in membrane trafficking and vesicle transport from the Golgi complex, is upregulated in endurant individuals. Yet, arafgap1 interacts with copz1 (Fig. 4), which codes for a coatomer (i.e., a protein complex that associates with Golgi coated vesicles and mediate transport from the endoplasmic reticulum). This protein-coding gene is up-regulated in burst-performant individuals, as well as rab12 and grasp, which both play a role in intracellular trafficking. We emit the hypothesis that endurant and burst-performant individuals differ in a range of downstream effectors, transcription regulators, molecules involved in cellular trafficking and microtubule activity in order to biosynthesize distinct extracellular matrix molecules and cell surface proteins, such as proteoglycans in the Golgi apparatus.

\section{Extracellular matrix and proteoglycans}

The extracellular matrix (ECM) is a primary macrostructure composed of several molecules such as collagen, hyaluronan, proteoglycans and glycoproteins that assemble into an organized meshwork [31, 43]. Proteoglycans for instance have diverse and essential roles in matrix remodeling and can act as receptors or co-receptors to affect signaling pathways but also to initiate and modulate signal transduction cascades independently of other receptors $[44,45]$. In this study, we highlighted the upregulation of genes coding members of two large groups of proteoglycans: neurocan (ncan), a chondroitin sulfate proteoglycan that is up-regulated in burst-performant 


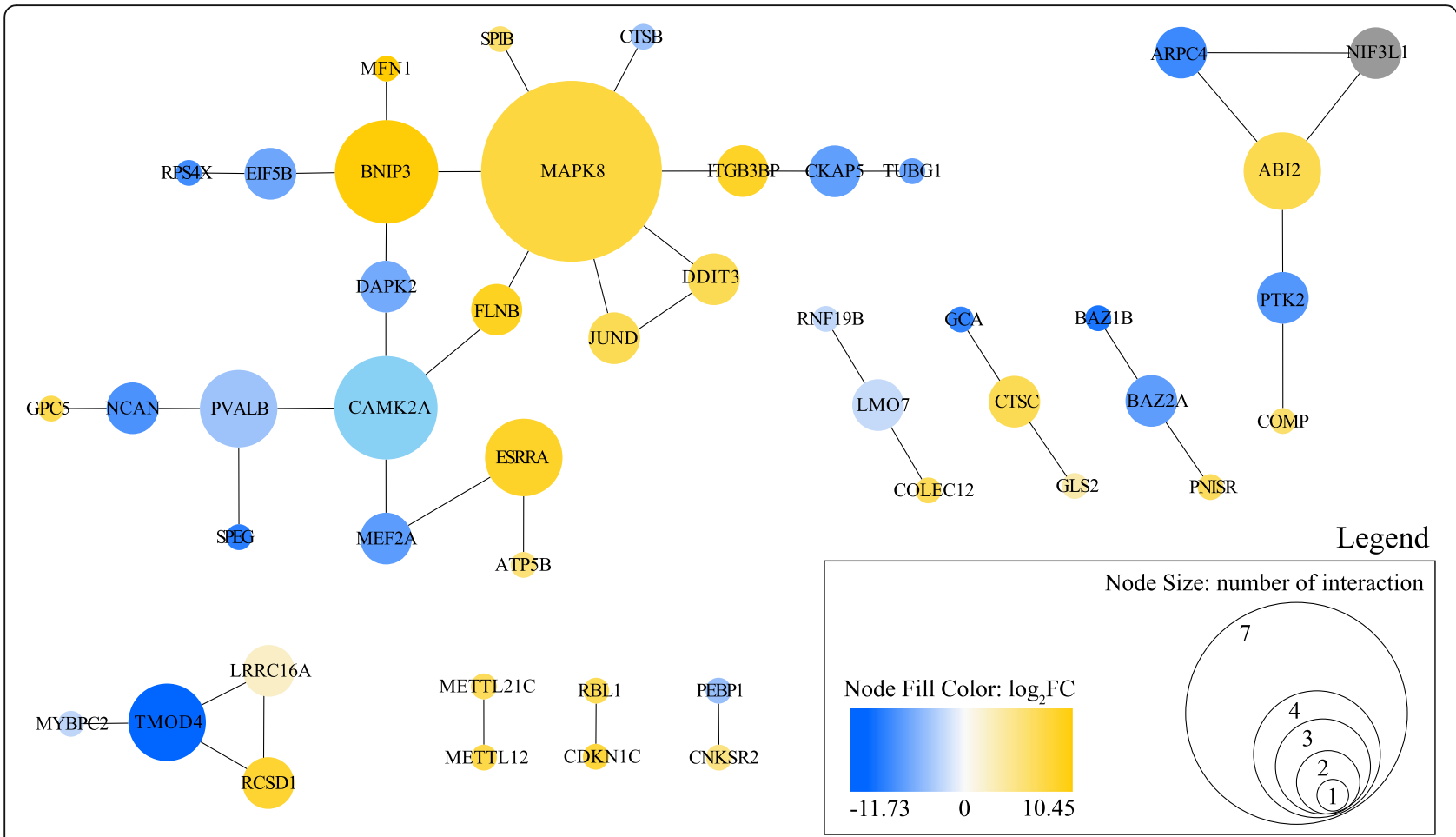

Fig. 4 Gene interaction networks that contain 46/109 differentially expressed transcripts between endurant and burst-performant individuals. Differentially expressed transcripts were analyzed using STRING [31] using gene symbols of human orthologous genes for analysis (see the supplementary table to find corresponding $X$. allofraseri annotated transcripts), and visual inspection was finalized using Cytoscape [32]. The node color is based on the $\log _{2} \mathrm{FC}$ of expression data, with negative (blue) and positive (yellow) values representing up-regulated transcript expression in endurant and burst-performant individuals, respectively (grey color correspond to gene with transcript isoforms expressed in both groups). Node size represents the number of interactions with other protein-coding genes and allows to rapidly visualize central genes

individuals, and glypican ( $g p c 5)$, a heparan sulfate proteoglycan that is up-regulated in endurant individuals. In addition, we found an up-regulation of a cartilage oligomeric matrix protein-like (comp) in endurant individuals that has the molecular functions to bind calcium, heparin or proteoglycans. Therefore, it is plausible that endurant and burst-performant individuals differ in the proteoglycans and other extracellular proteins synthesized because their diversity and properties make them advantageous for powerful bursts of speed or longduration exercise.

Chondroitin sulfates that partly compose aggrecan are able to absorb shocks by binding and releasing water content during compression in cartilaginous tissues, tendons, or ligaments $[46,47]$ which can protect against injury during short and powerful physical performance. In addition, it has been shown that glypican-1 is able to enhance growth factor activity and is therefore used in therapeutic treatment to create new vasculature and restore blood flow in ischemic tissues [48]. Therefore, there could be a link between $g p c 5$ and the positive relationship between endurance training and capillary densities [49], which may be beneficial for transporting oxygen to muscle
[50]. Interestingly, we also found ppox, which codes for an essential component of hemoglobin and myoglobin, and spib, a hematopoietic transcription factor, to be up-regulated in endurant individuals. The coupling of increased blood oxygenation and muscle microvasculature is expected to render the aerobic pathway used during prolonged exercise more efficient. Finally, the study of Mao and colleagues [51] suggests that spib could be phosphorylated and activated by mitogen-activated protein kinase 8 (mapk8), which is also up-regulated in endurant individuals, and is part of a vast network comprising numerous genes involved in lipid metabolism, mitochondrial activity, and stress responses.

\section{Lipid metabolism, mitochondrial activity and stress \\ response}

Almost all differentially expressed transcripts related to lipid metabolism, energy production, mitochondrial activity ( $m f n 1$, esrra, atp5b, dgat2, gls2, nfs1) are upregulated in endurant individuals compared to burstperformant individuals. Yet, one protein-coding gene, a A-kinase anchor protein 1 (akap1), has 2 transcript isoforms, one being up-regulated in burst-performant and 
one in endurant individuals. Those splice variants are proteins found in the mitochondria transmembrane, but at different position (position 7-26 and 42-61 in burstperformant and endurant individuals, respectively). The A-kinase anchor protein 1 binds to different regulatory subunits of protein kinase A (PKA) that has regulatory properties in lipid, sugar, and glycogen metabolism. Interestingly, we found an up-regulation of $f s d 2$ in burst-performant individuals, which is an important paralog of CMYA5 that mediates subcellular compartmentation of protein kinase A and may attenuate the ability of calcineurin to induce a slow-fiber gene program in muscle [52]. Thus, we suggest that alternative splicing of akap1, in association with other mitochondrial or cytoplasmic genes, is a mechanism enabling the shift between different types of metabolism in endurant and burst-performant individuals.

Furthermore, our results are consistent with the fact that endurant individuals rely preferentially on lipid metabolism, because oxidative phosphorylation of fatty acids in muscle mitochondria produces a high yield of ATP, necessary for prolonged contraction of muscle fibers $[53,54]$. On the contrary, individuals excelling at burst performance may rely mostly on anaerobic glycolysis in the cytosol (fast rate but low yield of ATP) [55]. In this context, we found diacylglycerol acyltransferase 2 (dgat2) to be up-regulated in endurant individuals. This endoplasmic reticulum enzyme catalyzes the final step in triglyceride synthesis and is part of the glycerolipid metabolism [56]. In addition, we found an up-regulation of $a t p 5 b$, a mitochondrial ATP synthase subunit, by the estrogen-related receptor $\alpha$ (ERR $\alpha$, coded by esrra) that regulates the transcription of metabolic genes and has a role in oxidative metabolism (Fig. 4) [57, 58]. ERR $\alpha$ has been found to be under control of myocyte enhancer factor 2 (MEF2) [59], a transcription factor that belongs to the MADS-box superfamily and that activates numerous muscle specific, growth factor-induced and stressinduced genes $[60,61]$. Yet, we found a transcript that matches the mRNA of myocyte enhancer factor $2 \mathrm{~A} \mathrm{~L}$ homoeolog of Xenopus laevis (mef $2 a$ ) to be up-regulated in burst-performant individuals. This transcript has a non-synonymous mutation in the coding part of the MADS-box protein domain (Arg4Lys) which is responsible for DNA recognition and cofactor interaction. Therefore, it is not clear if the mef $2 a$ transcript of our study negatively regulates esrra (and also $k t n 1$ ) expression or if it activates another gene that has yet to be identified. Intriguingly, we found an upregulation of an inhibitor of cyclin-dependent kinase (CDKI xic1) in endurant individuals, while cyclindependent kinase (CDK5) has been found to inhibit MEF2 [62].
Several studies have suggested a link between the MEF2 family of transcription factors and calciumdependent signaling pathways $[63,64]$. Calcium signaling is known to be essential for increasing endurance, oxidative capacity, and mitochondrial biogenesis $[65,66]$. Likewise, we found an up-regulation in endurant individuals of the calcium/calmodulindependent protein kinase (CAMK) 2 A (camk2a) along with filamin B $(f \ln b)$, an actin-binding protein (Fig. 4). Interestingly, CAMKs have also been found to activate mitogen-activated protein kinase (MAPK) which mediates early gene expression in response to various cell stimuli. Consistently, mapk8, which is upregulated in endurant individuals, is known to positively regulate the expression of bnip3, an apoptosisinducing protein located in the outer mitochondrial membrane [67]. On the contrary, bnip3 is negatively controlled by the translation initiation factor $5 \mathrm{~B}$ (eif5b) [68], the latter having an increased expression in burst-performant individuals, along with the ribosomal protein $\mathrm{S} 4$ (rps $4 x)$ and the ribosomal protein S6 kinase a4 (rps6ka4). Noticeably, Clarke and colleagues [69] predicted the translation factor Eif6 to be a key regulator of energy metabolism, affecting mitochondrial respiration efficiency, reactive oxygen species (ROS) production, and exercise performance. Also, mapk8 and a transcription factor jun-D-like (jund) interact with ddit3 (Fig. 4) which encodes a member of the C/EBP family of transcription factors implicated in adipogenesis, erythropoiesis or promoting apoptosis, and which has two transcript isoforms upregulated in endurant individuals and one transcript isoform up-regulated in burst-performant individuals.

We found a notable relationship between the calcium signaling pathway and stress-induced genes that are upregulated in either endurant or burst-performant individuals. This is consistent with previous reports of a link between endoplasmic reticulum (ER) stress, unfolded protein response, and the contractile activity of muscle $[70,71]$ and suggests a need to further recycle damaged proteins and organelles that are used during muscle activity [72]. For instance, one of those actively used proteins during contraction and relaxation of the muscle is the calcium cycling protein parvalbumin that reduces the free calcium concentration in the sarcoendoplasmic reticulum and cytoplasm [73, 74]. In our study, ocm4.1, which codes for a protein that belongs to the paravalbumin family, is significantly up-regulated in burst performant frogs compared to endurant individuals. Similarly, the paravalbumin gene (pvalb) was found to be highly expressed in beltfish (Trichiurus lepturus), a fish species with high swimming activity [75] and particularly associated with fast contracting muscle fibers [76]. 


\section{Rho-GTPases, ARP2/3 and WAVE complexes, and actin cytoskeleton}

Many studies interested in physical performance in general and performance trade-offs in particular, have focused on the physiological aspects of muscle and particularly on fiber type differences [12, 77]. Whereas one major factor contributing to the differences in contractile properties between fiber types is the presence of different myosin heavy chain (MHC) isoforms [78, 79], we found the third most up-regulated transcripts in burst-performant individuals (LOC108701289) to be an ortholog of Xenopus tropicalis speg gene, which encodes a protein with similarity to members of the myosin light chain kinase family. In addition, we primarily found genes involved in the polymerization and depolymerization of the actin filament to be differentially expressed between endurant and burst-performant individuals. Indeed, the network of actin and actin binding proteins, along with the microtubules and intermediate filaments, constituting the actin cytoskeleton of skeletal striated muscle, is highly dynamic and allows crucial processes like cell migration and division, signal transduction, organelle transport and coordination of muscle contraction [33]. This dynamic system is made possible through the reversible polymerization of globular actin monomers (G-actin) into filaments (F-actin) [80].

Polymerization and depolymerization of the actin filaments is the culmination of a signaling cascade that begins with extracellular stimulation, adhesion interaction (ECM cell-cell interaction) or mechanical stress, which then acts upon guanine-nucleotide-exchange factors (GEFs) and GTPase-activating proteins (GAPs) to control the activation state of the small GTPases Rho, Rac, and Cdc42. After activation, the GTPases bind to a variety of effectors to stimulate downstream signaling pathways [81]. For instance, the non-receptor protein kinase 2 (ptk2, up-regulated in burst-performant individuals) can modulate the RhoA regulation pathway, but also activates MAP kinase signaling cascade and mediates activation of the Rho GTPase rac1. Rac1 activates the WAVE regulatory complex that drives Arp2/3 complexmediated actin polymerization [82]. In our study, arpc4, an actin-binding component of the Arp2/3 complex is up-regulated in burst-performant individuals, whereas abi2, coding a component of the WAVE complex, is upregulated in endurant individuals. Interestingly, we found two isoforms of the nif $3 l 1$ gene, one isoform being up-regulated in endurant individuals, the other in burstperformant individuals. This gene may function as a transcriptional corepressor and interacts with arpc4 and abi2 in the network involving also ptk2 and comp (Fig. 4). Further examination would be necessary to test the hypothesis that the two isoforms of the nif3l1 transcript serve as a switch to activate or inhibit proteins of the
WAVE and ARP2/3 complex, and thus actin polymerization.

Additionally, we found two up-regulated genes in endurant individuals that are responsible for the actin thin filament length. An F-actin uncapping protein, lrrc16a, generates uncapped barbed ends that enhance actin polymerization, as well as a CapZ-interacting protein, $r c s d 1$, which induces phosphorylation of CapZIP and regulates the ability of the F-actin-capping protein to remodel actin filament assembly. Antagonistically, the tropomodulin-4 gene $(\bmod 4)$ is up-regulated in burst performant individuals and codes for a type of actincapping protein that blocks the depolymerization of the actin filaments at the pointed end, thus contributing to the formation of short actin protofilaments. In one network, this gene interacts with a myosin-binding protein $\mathrm{C}$ fast-type $(m y b p c 2)$ for which we find two different upregulated transcripts in burst-performant individuals (Figs. 3, 4). These two transcripts are globally dissimilar, which suggests the presence of two mybpc2 homoeologs in the allotetraploid Xenopus allofraseri. Homoeologs are homologous genes in the same species that started diverging through speciation but were reunified in the same genome by allopolyploidization [83]. The upregulation of mybpc 2 transcription in burst performant individuals, along with the over-expression of tmod4, may lead to the creation and renewal of a short fast-type actin-like filament, necessary for fast and powerful locomotion. Therefore, it seems that there is further depolymerization and polymerization of the actin filaments in respectively burst-performant and endurant individuals, and this may be linked to the need to rapidly recycle and rearrange or to stabilize the actin cytoskeleton.

\section{Conclusions}

Locomotor performance trade-offs have received considerable attention in the literature over the past three decades [11, 13, 84-87], yet the molecular origins of such trade-offs remain unclear. Because locomotor performance is heritable [14-16], substantial effort has been devoted to uncover its molecular basis. However, contradictory results regarding candidate genes suggest that locomotor performance is a complex polygenic trait and that gene expression regulation could be a nonnegligible factor. Accordingly, our study reveals numerous transcription factors (DNA and RNA binding), ribosomal proteins, protein kinase, ubiquitin ligase, methyltransferase, and effectors of the signaling cascade that may help explain the trade-off between burst performance and endurance observed in male Xenopus allofraseri. Specifically, endurant individuals show an overexpression of protein-coding genes related directly or indirectly to lipid metabolism, mitochondrial activity, ATP 
production and muscle oxygen supply. Moreover, endurant individuals appear to have increased actin polymerization, whereas burst-performant individuals have increased actin depolymerization along with an upregulation of two fast-type myosin-binding protein $\mathrm{C}$ transcripts. Finally, burst-performant and endurant individuals show several differentially expressed transcripts coding for proteoglycans and extracellular matrix proteins, or proteins involved in intracellular trafficking, apoptosis and the ER stress response. Interestingly, several differentially expressed protein-coding genes are involved in both the calcium signaling and mitogenactivated pathways. How, and if, this relationship could explain the evolution of performance trade-offs remains unclear and would require further investigation.

Previous studies in humans have shown that differences in fiber type can be affected by a stop codon polymorphism (R577X) at actn3 [88, 89] and this same mutation can alter muscle function in mice [90]. Yet, there are contradictory results regarding the effects of actn3 polymorphism to explain performance trade-offs in humans [91]. In our study, none of the transcripts corresponding to actn 3 or any member of the $\alpha$-actin binding protein gene family were differentially expressed. The great variation observed within or between species for muscle fiber type composition can be attributed to the use of alternative splice forms by structural proteins [92]. Indeed, the regulation of, for instance, alternative splicing plays a major role in the production of functional complexity [93] and interestingly, a previous study detected an association between flight performance in dragonflies and alternative splicing in relation to muscle calcium sensitivity [94]. In our study, we found key genes (akap1 for metabolism, ddit3 for apoptosis, ranbp3 for nuclear export, nif3l1 as a transcriptional corepressor) with transcript isoforms expressed in either burst-performant or endurant individuals. Although our results are biologically meaningful, we want to acknowledge that we were not able to validate these observations by quantitative methods such as RT-QPCR. In addition, RNAseq and qPCR results are known to be closely correlated [95] and the confirmation of these results would rather require testing additional samples. Finally, future studies dedicated to clarify the critical role of alternative splicing and its regulatory mechanism in explaining physical performance trade-offs would be insightful.

\section{Methods}

\section{Model species}

Eight Xenopus allofraseri males were caught in the wild (December 2009) in a single pond between Manengoteng (N 04.8090, E 09.8011) and Manjo (N 04.8435, E 09.8218) in Cameroon (Fig. 2). Animals were exported to France with authorization from the Cameroonian Ministry of Forestry and Wildlife (MINFOF) and were housed at the National Museum of Natural History in Paris, France. Frogs were placed in aquaria $(60 \times 30 \times 30$ $\mathrm{cm})$ at $24^{\circ} \mathrm{C}$ and fed every week with beef heart, earthworms or mosquito larvae ad libitum. All individuals were pit tagged (Nonatec, Rodange, Luxembourg) for permanent identification.

\section{Physical performance}

Performance traits were measured for the eight males at a fixed temperature of $24^{\circ} \mathrm{C}$. Maximal exertion capacity was measured by chasing each individual down a threemeter long circular terrestrial track until exhaustion, as indicated by the lack of a righting response. The floor of the track was covered with moistened cork to improve traction and prevent dehydration. For each individual, we recorded both the total distance covered and time spent moving until exhaustion. Burst performance capacity was quantified by measuring maximal instantaneous swimming speed and acceleration (see additional information about materials and measurement protocol in [8]). From the four physical performance traits, we performed a Principal Component Analysis (PCA) followed by an agglomerative hierarchical clustering using respectively the ade4 and FactoMineR packages of the R software.

\section{Illumina transcriptome sequencing and de novo assembly} The individuals used for performance measurements were euthanized with a lethal injection of sodium pentobarbital (dosage of $150 \mathrm{mg} / \mathrm{kg}$ ), a chemical compound acting quickly on the central nervous system, rendering the animal unconscious with little distress (a method validated by the European Commission (https://op. europa.eu/s/olzw). The knee extensor muscles of the right leg were extracted for subsequent RNA sequencing. Tissues were extracted, transferred to labeled tubes containing RNA-later and conserved at $-80^{\circ} \mathrm{C}$ until further processing. The protocol for RNA extraction using Trizol, RNA quantification and quality checking can be found in Dhorne-Pollet et al. [96]. PolyA-RNA was isolated and sequencing libraries prepared using ScriptSeq (Illumina). Pooled libraries were 100 paired-end sequenced using an Illumina HiSeq 2500 located at the University of Exeter Sequencing Service facility.

Paired-end sequence reads were pooled together to generate a de novo transcriptome assembly. The raw sequence reads were trimmed and Illumina adapters emoved using Trimmomatic [97] with the following parameters: leading:5 trailing:5 slidingwindow:4:15 minlen:36. Transcriptome assembly was then performed de novo with the program Trinity [98]. We assessed the completeness of our transcriptome assembly by 
searching for a tetrapod set of 3950 orthologs using BUSCO version 4.0.2 [99]. To obtain assembly quality statistics, paired-end reads were aligned back to the assembly with Bowtie2 [100]. A high-quality transcriptome assembly is expected to have strong representation of the reads input to the assembler and specifically for a trinity transcriptome assembly at least $80 \%$ of reads should mapped back to the assembly and exist as proper pairs. Transcript-level abundance was estimated using Kallisto [101], in addition to a normalized measure of transcript expression (TPM).

\section{Phylogenetic analysis}

To evaluate the phylogenetic position of the eight Xenopus males, we implemented a phylogenetic analysis with previously published mitogenomes of most known Хenopus species downloaded from GenBank [102] (Table S2). We retrieved reads mapping to the mitochondrial genome and performed a reference-based assembly of the complete mitochondrial genome for each sample using Geneious (www.geneious.com) and the Xenopus allofraseri mtDNA sequence [98]. We used MAFFT v.7 to compute a multiple alignment of all Xenopus mtDNA [103]. From this multiple alignment, we discarded the control region and all positions with too many gaps or misalignments using Gblocks. The phylogeny was then constructed using PhyML v.3.0 [30] including the Shimodaira-Hasegawa $(\mathrm{SH})$ statistic test. For visualization purposes, the phylogenetic tree was designed using Figtree v.1.4.4 [104] (Fig. 2).

\section{Differential expression analysis}

To detect differentially expressed transcripts, we ran edge $R$ [105], integrated in the $R$ Bioconductor suite [106], using as input the TPM expression values that were cross-sample normalized using the Trimmed Mean of M-values (TMM) method. We chose edgeR rather than DESeq2 as it can detect differentially expressed transcripts between our two conditions even for transcripts that are expressed at low levels, and in cases where there is high variability between the biological replicates, as we observed during data exploration. Differentially expressed transcripts were defined by a $\log _{2}$ fold change ( $\left.\log _{2} \mathrm{FC}\right)$ of 2 between burst-performant and endurant groups, and a false discovery rate (FDR) of 0.05. Expression data analysis using Volcano and heatmap plots relied on transcripts identified using the Trinity analysis framework.

\section{Transcript annotation}

We compared the significantly differentially expressed transcript sequences to the combined proteomes of Xenopus laevis and Xenopus tropicalis extracted from the Uniprot database using BLAST. We manually annotated the transcript sequences lacking detectable protein homologies by comparing them to the nucleotide $(\mathrm{nr} / \mathrm{nt})$ database using BLASTN with an $e$-value threshold of $1 \mathrm{e}^{-5}$. Differentially expressed transcripts were analyzed using STRING [107]. The STRING database allows the construction of protein-protein interaction networks, ranging from direct protein-protein interactions to indirect interactions (such as coexpression and text mining). The human database was selected for the network analysis as it contained substantially more information than the one for Xenopus tropicalis (the STRING database does not include data for Xenopus laevis). Gene symbols for each protein were used to find human orthologues and generate STRING networks using default settings. TSV files with interaction data were then exported and processed using Cytoscape [32] for visual inspection.

\section{Abbreviations}

FDR: False-discovery rate; logFC: Log2 fold-change; mybpc2: Myosin-binding protein C fast-type; PCA: Principal component analysis; FAK: Focal adhesion kinase; FRNK: FAK-related non-kinase; ECM: Extracellular matrix; ROS: Reactive oxygen species; ER: Endoplasmic reticulum; MHC: Myosin heavy chain; GEFs: Guanine-nucleotide-exchange factors; GAPs: GTPase-activating proteins; ATP: Adenosin-triphosphate; RT-qPCR: Reverse transcription quantitative PCR; RNAseq: RNA sequencing; MINFOF: Cameroonian ministry of forestry and wildlife; TPM: Transcripts per million; SH: Shimodaira-hasegawa;

TMM: Trimmed mean of M-values

\section{Supplementary Information}

The online version contains supplementary material available at https://doi. org/10.1186/s12864-021-07517-1.

Additional file 1: Table S1. Up- and down-regulated differentially expressed transcripts ( $n=103$ that match 90 unique protein-coding genes) in the endurant group compared to the burst-performant group based on edgeR method.

Additional file 2: Table S2. Species name with their corresponding accession numbers of mitochondrial sequences downloaded from GenBank and used in the phylogenetic analysis.

\section{Acknowledgements}

We would like to thank Michel Baguette and Hervé Philippe for providing valuable resources and discussion. We would like to thank Eric Fokam and Legrand Nono Gonwouo for their help in the field and without whom this study would not have been possible. We want to thank the Sequencing Service and Computational core facilities at the University of Exeter for producing quality RNA-seq data. We also want to thank the IUCN red list for making the spatial data publicly available.

\section{Authors' contributions \\ $\mathrm{AJR}, \mathrm{CB}$ and $\mathrm{AH}$ conceived and designed the study; MV and $\mathrm{AH}$ collected the samples; $\mathrm{AH}$ and CB measured the locomotor performance; MV and TS performed the RNA extraction; KM and KP performed the RNA sequencing; AJR assembled the de novo transcriptome; NP performed the quality control of transcriptome assembly, the phylogenetic analysis, and provided support with the analyses; VD conducted the differential expression analysis, annotation, protein network, statistical analysis, wrote and illustrated the manuscript; All authors read and approved the final manuscript.}

Funding

Support for this work was provided by the Agence Nationale de la Recherche (ANR; France) MOBIGEN [ANR- 09-PEXT-003]. RNA-seq data was produced by the Sequencing Service and Computational core facilities at the 
University of Exeter with generous support from Medical Research Council Clinical Infrastructure award (MR/M008924/1), Wellcome Trust Institutional Strategic Support Fund (WT097835MF), Wellcome Trust Multi User Equipment Award (WT101650MA) and BBSRC LOLA award (BB/K003240/1).

\section{Availability of data and materials}

The annotation of the 109 differentially expressed transcripts and the STRING TSV interaction file are available on Zenodo (https://doi.org/10.5281/zenodo. 4028544). Processed and raw data files generated by this transcriptomic analysis have been deposited in NCBI's Gene Expression Omnibus [108] and are accessible through GEO Series accession number GSE157915 (https:// www.ncbi.nlm.nih.gov/geo/query/acc.cgi?acc=GSE157915). The geographic ranges of Xenopus species are publicly available at the IUCN red list website (https://www.iucnredlist.org/). Species name with their corresponding accession numbers of mitochondrial sequences downloaded from GenBank and used in the phylogenetic analysis are indicated in Table S2.

\section{Declarations}

\section{Ethics approval and consent to participate}

Animals were exported to France with the authorization for export from the Cameroonian Ministry of Forestry and Wildlife (MINFOF). All applicable international, national, and/or institutional guidelines for the care and use of animals were followed. All experiments were approved by the Institutional ethics committee at the National Museum of Natural History in Paris (\#6825). In accordance to the directive 2010/63/EU of the European Parliament and French legislation, our study did not require specific authorization because our observations did not cause any pain, suffering, distress, or lasting harm.

\section{Consent for publication}

Not applicable.

\section{Competing interests}

The authors declare that they have no competing interests.

\section{Author details}

${ }^{1}$ UMR 7179 MECADEV, C.N.R.S/M.N.H.N., Département Adaptations du Vivant, 55 Rue Buffon, 75005 Paris, France. ²Station d'Ecologie Expérimentale du CNRS, USR 2936, 09200 Moulis, France. ${ }^{3}$ Functional Ecology Lab, Department of Biology, University of Ottawa, 30 Marie Curie, Ottawa, ON K1N 6N5, Canada. ${ }^{4}$ Evolution, Génomes, Comportement \& Ecologie, Université Paris-Saclay, CNRS, IRD, 91198 Gif-sur-Yvette, France. ${ }^{5}$ Exeter Sequencing Service, College of Life and Environmental Sciences, University of Exeter, Exeter EX4 4QD, UK. ${ }^{6}$ Centre for Ecology \& Conservation, College of Life and Environmental Sciences, University of Exeter, Penryn, Cornwall, UK. ${ }^{7}$ Evolutionary Morphology of Vertebrates, Ghent University, B-9000 Ghent, Belgium.

Received: 17 September 2020 Accepted: 8 March 2021 Published online: 23 March 2021

\section{References}

1. Irschick DJ, Garland T Jr. Integrating function and ecology in studies of adaptation: investigations of locomotor capacity as a model system. Annu Rev Ecol Evol Syst. 2001;32(1):367-96. https://doi.org/10.1146/annurev. ecolsys.32.081501.114048.

2. Le Galliard J-F, Clobert J, Ferrière R. Physical performance and darwinian fitness in lizards. Nature. 2004;432(7016):502-5. https://doi.org/10.1038/na ture03057.

3. Husak JF, Fox SF, Lovern MB, Van Den Bussche RA. Faster lizards sire more offspring: sexual selection on whole-animal performance. Evolution. 2006; 60(10):2122-30. https://doi.org/10.1111/j.0014-3820.2006.tb01849.x.

4. Van Damme R, Wilson RS, Vanhooydonck B, Aerts P. Performance constraints in decathletes. Nature. 2002;415(6873):755-6. https://doi.org/10.1 038/415755b.

5. Stephens PR, Wiens JJ. Testing for evolutionary trade-offs in a phylogenetic context: ecological diversification and evolution of locomotor performance in emydid turtles. J Evol Biol. 2008;21(1):77-87. https://doi.org/10.1111/j.142 0-9101.2007.01467.x.
6. Dlugosz EM, Chappell MA, McGillivray DG, Syme DA, Garland T Jr. Locomotor trade-offs in mice selectively bred for high voluntary wheel running. J Exp Biol. 2009;212(Pt 16):2612-8. https://doi.org/10.1242/jeb.02 9058.

7. Oufiero CE, Walsh MR, Reznick DN, Garland T Jr. Swimming performance trade-offs across a gradient in community composition in Trinidadian killifish (Rivulus hartii). Ecology. 2011;92(1):180-79.

8. Herrel A, Bonneaud C. Trade-offs between burst performance and maximal exertion capacity in a wild amphibian, Xenopus tropicalis. J Exp Biol. 2012; 215(17):3106-11. https://doi.org/10.1242/jeb.072090.

9. Vanhooydonck B, James RS, Tallis J, Aerts P, Tadic Z, Tolley KA, Measey GJ, Herrel A. Is the whole more than the sum of its parts? Evolutionary tradeoffs between burst and sustained locomotion in lacertid lizards. Proc Biol Sci. 2014;281(1777):20132677.

10. Komi PV. Physiological and biomechanical correlates of muscle function: effects of muscle structure and stretch-shortening cycle on force and speed. Exerc Sport Sci Rev. 1984;12(1):81-122.

11. Garland T Jr. Genetic basis of activity metabolism. I. Inheritance of speed, stamina, and antipredator displays in the garter snake Thamnophis sirtalis. Evolution. 1988;42(2):335-50. https://doi.org/10.1111/j.1558-5646.1 988.tb04137.x.

12. Bonine $K E$, Gleeson TT, Garland T Jr. Comparative analysis of fiber-type composition in the iliofibularis muscle of Phrynosomatid lizards (Squamata). J Morphol. 2001;250(3):265-80. https://doi.org/10.1002/jmor.1069.

13. Wilson RS, James RS. Constraints on muscular performance: trade-offs between power output and fatigue resistance. Proc Biol Sci. 2004;271:S222-5.

14. Moore JS, Gow JL, Taylor EB, Hendry AP. Quantifying the constraining influence of gene flow on adaptive divergence in the lake-stream threespine stickleback system. Evolution. 2007;61(8):2015-26. https://doi. org/10.1111/j.1558-5646.2007.00168.x.

15. Rico-Sanz J, Rankinen T, Joanisse DR, Leon AS, Skinner JS, Wilmore JH, Rao DC, Bouchard C, Study HF. Familial resemblance for muscle phenotypes in the HERITAGE family Study. Med Sci Sports Exerc. 2003;35(8):1360-6. https:// doi.org/10.1249/01.MSS.0000079031.22755.63.

16. Costa AM, Breitenfeld L, Silva AJ, Pereira A, Izquierdo M, Marques MC: Genetic inheritance effects on endurance and muscle strength. An updateSports Med 2012, 42(6):449-458, DOl: https://doi.org/10.2165/11 650560-000000000-00000.

17. Bray MS, Hagberg JM, Pérusse L, Rankinen T, Roth SM, Wolfarth B, Bouchard $C$. The human gene map for performance and health-related fitness phenotypes. Med Sci Sports Exerc. 2009;41(1):35-73. https://doi.org/10.1249/ mss.0b013e3181844179.

18. Hagberg JM, Rankinen T, Loos RJ, Perusse L, Roth SM, Wolfarth B, Bouchard C. Advances in exercise, fitness, and performance genomics in 2010. Med Sci Sports Exerc. 2011;43(5):743-52. https://doi.org/10.1249/MSS.0b013e31 $82155 \mathrm{~d} 21$.

19. Sarzynski MA, Loos RJ, Lucia A, Perusse L, Roth SM, Wolfarth B, Rankinen T, Bouchard C. Advances in exercise, fitness, and performance genomics in 2015. Med Sci Sports Exerc. 2016;48(10):1906-16. https://doi.org/10.1249/ MSS.0000000000000982.

20. Gazda MA, Andrade P, Afonso S, Dilyte J, Archer JP, Lopes RJ, Faria R, Carneiro M. Signatures of selection on standing genetic variation underlie athletic and navigational performance in racing pigeons. Mol Biol Evol. 2018;35(5):1176-89. https://doi.org/10.1093/molbev/msy030.

21. Kelly SA, Bell TA, Selitsky SR, Buus RJ, Hua K, Weinstock GM, Garland T Jr. Pardo-Manuel de Villena F, pomp D: a novel intronic single nucleotide polymorphism in the myosin heavy polypeptide 4 gene is responsible for the mini-muscle phenotype characterized by major reduction in hind-limb muscle mass in mice. Genetics. 2013;195(4):1385-95. https://doi.org/10.1534/ genetics.113.154476.

22. Ricard A, Robert C, Blouin C, Baste F, Torquet G, Morgenthaler C, Riviere J, Mach N, Mata X, Schibler L, et al. Endurance exercise ability in the horse: a trait with complex polygenic determinism. Front Genet. 2017;8:89. https:// doi.org/10.3389/fgene.2017.00089.

23. Kim J, Williams FJ, Dreger DL, Plassais J, Davis BW, Parker HG, Ostrander EA. Genetic selection of athletic success in sport-hunting dogs. Proc Natl Acad Sci U S A. 2018;115(30):E7212-21. https://doi.org/10.1073/pnas.1800455115.

24. Ehlert T, Simon P, Moser DA. Epigenetics in sports. Sports Med. 2013;43(2): 93-110. https://doi.org/10.1007/s40279-012-0012-y.

25. Liu Y, Li M, Ma J, Zhang J, Zhou C, Wang T, Gao X, Li X. Identification of differences in microRNA transcriptomes between porcine oxidative and 
glycolytic skeletal muscles. BMC Mol Biol. 2013;14(7). https://doi.org/10.11 86/1471-2199-14-7.

26. Chen JF, Mandel EM, Thomson JM, Wu Q, Callis TE, Hammond SM, Conlon FL, Wang DZ. The role of microRNA-1 and microRNA-133 in skeletal muscle proliferation and differentiation. Nat Genet. 2006;38(2):228-33. https://doi. org/10.1038/ng1725

27. Keller P, Vollaard NB, Gustafsson T, Gallagher IJ, Sundberg CJ, Rankinen T, Britton SL, Bouchard C, Koch LG, Timmons JA. A transcriptional map of the impact of endurance exercise training on skeletal muscle phenotype. J Appl Physiol. 2011;110(1):46-59.

28. Caetano-Anolles K, Rhodes JS, Garland T Jr, Perez SD, Hernandez AG, Southey BR, Rodriguez-Zas SL. Cerebellum transcriptome of mice bred for high voluntary activity offers insights into locomotor control and rewarddependent behaviors. PLoS One. 2016;11(11):e0167095. https://doi.org/10.13 71/journal.pone.0167095.

29. IUCN 2020. The IUCN red list of threatened species. Version 2020-2. [https:// www.iucnredlist.org/. Downloaded on 15 July 2020].

30. Guindon S. Dufayard JF, Lefort V, Anisimova M, Hordijk W, Gascuel O: new algorithms and methods to estimate maximum-likelihood phylogenies: assessing the performance of PhyML 3.0. Syst Biol. 2010;59(3):307-21. https://doi.org/10.1093/sysbio/syq010.

31. Yue B. Biology of the extracellular matrix. J Glaucoma. 2014;23(8 Suppl 1): S20-3. https://doi.org/10.1097/IJG.0000000000000108.

32. Shannon P, Markiel A, Ozier O, Baliga NS, Wang JT, Ramage D, Amin N, Schwikowski B, Ideker T. Cytoscape: a software environment for integrated models of biomolecular interaction networks. Genome Res. 2003;13(11): 2498-504. https://doi.org/10.1101/gr.1239303.

33. Henderson CA, Gomez CG, Novak SM, Mi-Mi L, Gregorio CC. Overview of the muscle cytoskeleton. Compr Physiol. 2017;7(3):891-944. https://doi.org/1 0.1002/cphy.c160033.

34. Wu C. Focal adhesion. A focal point in current cell biology and molecular medicine. Cell Adhes Migr. 2007;1(1):7-12

35. Graham ZA, Gallagher PM, Cardozo CP. Focal adhesion kinase and its role in skeletal muscle. J Muscle Res Cell Motil. 2015;36(4-5):305-15. https://doi. org/10.1007/s10974-015-9415-3.

36. Klossner S, Durieux A-C, Freyssenet D, Flueck M. Mechano-transduction to muscle protein synthesis is modulated by FAK. Eur J Appl Physiol. 2009; 106(3):389-98. https://doi.org/10.1007/s00421-009-1032-7.

37. Durieux A-C, D'Antona G, Desplanches D, Freyssenet D, Klossner S, Bottinelli $R$, Flück M. Focal adhesion kinase is a load-dependent governor of the slow contractile and oxidative muscle phenotype. J Physiol. 2009;587(14):370317. https://doi.org/10.1113/jphysiol.2009.171355.

38. Klossner S, Li R, Ruoss S, Durieux A-C, Flück M. Quantitative changes in focal adhesion kinase and its inhibitor, FRNK, drive load-dependent expression of costamere components. Am J Phys Regul Integr Comp Phys. 2013;305(6): R647-57. https://doi.org/10.1152/ajpregu.00007.2013.

39. Vignal E, Blangy A, Martin M, Gauthier-Rouviere C, Fort P. Kinectin is a key effector of RhoG microtubule-dependent cellular activity. Mol Cell Biol. 2001; 21(23):8022-34. https://doi.org/10.1128/MCB.21.23.8022-8034.2001

40. Dick G, Akslen-Hoel LK, Grondahl F, Kjos I, Prydz K. Proteoglycan synthesis and Golgi organization in polarized epithelial cells. J Histochem Cytochem. 2012;60(12):926-35. https://doi.org/10.1369/0022155412461256.

41. Zhu X, Kaverina I. Golgi as an MTOC: making microtubules for its own good. Histochem Cell Biol. 2013;140(3):361-7. https://doi.org/10.1007/s00418013-1119-4.

42. Brunet N, Morin A, Olofsson B. RhoGDI-3 regulates RhoG and targets this protein to the Golgi complex through its unique N-terminal domain. Traffic. 2002;3(5):342-58. https://doi.org/10.1034/j.1600-0854.2002.30504.x.

43. Frantz C, Stewart KM, Weaver VM. The extracellular matrix at a glance. J Cell Sci. 2010;123(Pt 24):4195-200. https://doi.org/10.1242/jcs.023820.

44. Elfenbein A, Simons M. Auxiliary and autonomous proteoglycan signaling networks. Methods Enzymol. 2010;480:3-31. https://doi.org/10.1016/S00766879(10)80001-1.

45. Walimbe T, Panitch A. Proteoglycans in biomedicine: resurgence of an underexploited class of ECM molecules. Front Pharmacol. 2019;10:1661.

46. Smith RKW, Goodship AE. Chapter 2.3 - Tendon and ligament physiology: responses to exercise and training. In: Equine Exercise Physiology, the Science of Exercise in the Athletic Horse. London: Elsevier Ltd; 2008. p. 106-31.

47. Screen HR, Berk DE, Kadler KE, Ramirez F, Young MF. Tendon functional extracellular matrix. J Orthop Res. 2015:33(6):793-9. https://doi.org/10.1002/ jor.22818.
48. Monteforte AJ, Lam B, Das S, Mukhopadhyay S, Wright CS, Martin PE, Dunn AK, Baker AB. Glypican-1 nanoliposomes for potentiating growth factor activity in therapeutic angiogenesis. Biomaterials. 2016;94:45-56. https://doi. org/10.1016/j.biomaterials.2016.03.048.

49. Cocks M, Shaw CS, Shepherd SO, Fisher JP, Ranasinghe AM, Barker TA, Tipton KD, Wagenmakers AJM. Sprint interval and endurance training are equally effective in increasing muscle microvascular density and eNOS content in sedentary males. J Physiol. 2013;591(3):641-56. https://doi.org/1 0.1113/jphysiol.2012.239566.

50. Spires J, Lai N, Zhou H, Saidel GM: Hemoglobin and myoglobin contributions to skeletal muscle oxygenation in response to exercise 2011, 701:347-352.

51. Mao C, Ray-Gallet D, Tavitian A, Moreau-Gachelin F. Differential phosphorylations of Spi-B and Spi-1 transcription factors. Oncogene. 1996; 12(4):863-73.

52. Kielbasa OM, Reynolds JG, Wu CL, Snyder CM, Cho MY, Weiler H, Kandarian $\mathrm{S}$, Naya FJ. Myospryn is a calcineurin-interacting protein that negatively modulates slow-fiber-type transformation and skeletal muscle regeneration. FASEB J. 2011;25(7):2276-86. https://doi.org/10.1096/fj.10-169219.

53. Horowitz JF, Klein S. Lipid metabolism during endurance exercise. Am J Clin Nutr. 2000;72(suppl):558S-63S. https://doi.org/10.1093/ajcn/72.2.558S.

54. Narkar VA, Downes M, Yu RT, Embler E, Wang YX, Banayo E, Mihaylova MM, Nelson MC, Zou Y, Juguilon H, Kang H, Shaw RJ, Evans RM. AMPK and PPARdelta agonists are exercise mimetics. Cell. 2008;134(3):405-15. https:// doi.org/10.1016/j.cell.2008.06.051.

55. Niemi AK, Majamaa K. Mitochondrial DNA and ACTN3 genotypes in Finnish elite endurance and sprint athletes. Eur J Hum Genet. 2005;13(8):965-9. https://doi.org/10.1038/sj.ejhg.5201438.

56. McLaren DG, Han S, Murphy BA, Wilsie L, Stout SJ, Zhou H, Roddy TP, Gorski $J \mathrm{~N}$, Metzger DE, Shin MK, et al. DGAT2 inhibition alters aspects of triglyceride metabolism in rodents but not in non-human primates. Cell Metab. 2018;27(6):1236-48 e1236. https://doi.org/10.1016/j.cmet.2018.04.004.

57. Villena JA, Hock MB, Chang WY, Barcas JE, Giguere V, Kralli A. Orphan nuclear receptor estrogen-related receptor alpha is essential for adaptive thermogenesis. Proc Natl Acad Sci. 2007;104(4):1418-23. https://doi.org/10.1 073/pnas.0607696104.

58. Tripathi M, Yen PM, Singh BK. Estrogen-related receptor alpha: an underappreciated potential target for the treatment of metabolic diseases. Int J Mol Sci. 2020;21(5):1645. https://doi.org/10.3390/ijms21051645.

59. van Rooij E, Fielitz J, Sutherland LB, Thijssen VL, Crijns HJ, Dimaio MJ, Shelton J, De Windt LJ, Hill JA, Olson EN. Myocyte enhancer factor 2 and class ii histone deacetylases control a gender-specific pathway of cardioprotection mediated by the estrogen receptor. Circ Res. 2010;106(1): 155-65. https://doi.org/10.1161/CIRCRESAHA.109.207084.

60. Kaushal S, Schneider J, Nadal-Ginard B, Mahdavi V. Activation of the myogenic lineage by MEF2A, a factor that induces and cooperates with MyoD. Science. 1994;266(5188):1236-40. https://doi.org/10.1126/science.7973707.

61. Erck C, Seidl K. MyoD and MEF2A mediate activation and repression of the p $75^{\mathrm{NGFR}}$ gene during muscle development. Biochem Biophys Res Commun. 1998;245(3):871-7. https://doi.org/10.1006/bbrc.1998.8533.

62. Tang X, Wang X, Gong X, Tong M, Park D, Xia Z, Mao Z. Cyclin-dependent kinase 5 mediates neurotoxin-induced degradation of the transcription factor myocyte enhancer factor 2. J Neurosci. 2005;25(19):4823-34. https:// doi.org/10.1523/JNEUROSCI.1331-05.2005.

63. Chin ER, Olson EN, Richardson JA, Yang Q, Humphries C, Shelton JM, Wu H, Zhu W, Bassel-Duby R, Williams SR. A calcineurin-dependent transcriptional pathway controls skeletal muscle fiber type. Genes Dev. 1998;12(16):2499509. https://doi.org/10.1101/gad.12.16.2499.

64. Wu H, Naya FJ, McKinsey TA, Mercer B, Shelton JM, Chin ER, Simard AR, Michel RN, Bassel-Duby R, Olson EN, Williams RS. MEF2 responds to multiple calcium-regulated signals in the control of skeletal muscle fiber type. EMBO J. 2000;19(9):1963-73. https://doi.org/10.1093/emboj/19.9.1963.

65. Naya FJ, Mercer B, Shelton J, Richardson JA, Sanders Williams R, Olson EN. Stimulation of slow skeletal muscle fiber gene expression by calcineurin in vivo. J Biol Chem. 2000;275(7):4545-8. https://doi.org/10.1074/jbc.275.7.4545.

66. Ojuka EO. Role of calcium and AMP kinase in the regulation of mitochondrial biogenesis and GLUT4 levels in muscle. Proc Nutr Soc. 2004; 63(2):275-8. https://doi.org/10.1079/PNS2004339.

67. Moriyama M, Moriyama H, Uda J, Kubo H, Nakajima Y, Goto A, Morita T, Hayakawa T. BNIP3 upregulation via stimulation of ERK and JNK activity is required for the protection of keratinocytes from UVB-induced apoptosis. Cell Death Dis. 2017;8(2):e2576. https://doi.org/10.1038/cddis.2017.4. 
68. Zeng W, Wan R, Zheng Y, Singh SR, Wei Y. Hypoxia, stem cells and bone tumor. Cancer Lett. 2011;313(2):129-36. https://doi.org/10.1016/j.canlet.2011. 09.023.

69. Clarke K, Ricciardi S, Pearson T, Bharudin I, Davidsen PK, Bonomo M, Brina D, Scagliola A, Simpson DM, Beynon RJ, Khanim F, Ankers J, Sarzynski MA, Ghosh S, Pisconti A, Rozman J, Hrabe de Angelis M, Bunce C, Stewart C, Egginton S, Caddick M, Jackson M, Bouchard C, Biffo S, Falciani F. The role of eif6 in skeletal muscle homeostasis revealed by endurance training coexpression networks. Cell Rep. 2017;21(6):1507-20. https://doi.org/10.1016/j. celrep.2017.10.040

70. Huang G, Yao J, Zeng W, Mizuno Y, Kamm KE, Stull JT, Harding HP, Ron D, Muallem S. ER stress disrupts Ca2+-signaling complexes and Ca2+ regulation in secretory and muscle cells from PERK-knockout mice. J Cell Sci. 2006;119(Pt 1):153-61. https://doi.org/10.1242/jcs.02731.

71. Deldicque L. Endoplasmic reticulum stress in human skeletal muscle: any contribution to sarcopenia? Front Physiol. 2013;4:236.

72. Ogata M, Hino S, Saito A, Morikawa K, Kondo S, Kanemoto S, Murakami T, Taniguchi M, Tanii I, Yoshinaga K, Shiosaka S, Hammarback JA, Urano F, Imaizumi K. Autophagy is activated for cell survival after endoplasmic reticulum stress. Mol Cell Biol. 2006;26(24):9220-31. https://doi.org/10.1128/ MCB.01453-06

73. Westerblad H, Allen DG. Slowing of relaxation and [Ca2+]i during prolonged tetanic stimulation of single fibres from Xenopus skeletal muscle. J Physiol. 1996;492(3):723-36. https://doi.org/10.1113/jphysiol.1996.sp021341.

74. Arif SH. A Ca (2+)-binding protein with numerous roles and uses: parvalbumin in molecular biology and physiology. Bioessays. 2009;31(4): 410-21. https://doi.org/10.1002/bies.200800170.

75. Zhang H, Audira G, Li Y, Xian W, Varikkodan MM, Hsiao CD. Comparative study the expression of calcium cycling genes in Bombay duck (Harpadon nehereus) and beltfish (Trichiurus lepturus) with different swimming activities. Genom Data. 2017;12:58-61. https://doi.org/10.1016/j.gdata.2017. 03.003.

76. Celio MR, Heizmann CW. Calcium-binding protein parvalbumin is associated with fast contracting muscle fibres. Nature. 1982;297(5866):504-6. https:// doi.org/10.1038/297504a0.

77. Rowlerson AM, Spurway NC. Histochemical and immunohistochemical properties of skeletal muscle fibres from Rana and Xenopus. Histochem J. 1988;20(12):657-73. https://doi.org/10.1007/BF01002746.

78. Pette D, Staron RS. Myosin isoforms, muscle fiber types, and transitions. Microsc Res Tech. 2000;50(6):500-9. https://doi.org/10.1002/1097-0029(2 0000915)50:6<500::AID-JEMT7>3.0.CO;2-7.

79. Greising SM, Gransee HM, Mantilla CB, Sieck GC. Systems biology of skeletal muscle: fiber type as an organizing principle. Wiley Interdiscip Rev Syst Biol Med. 2012;4(5):457-73. https://doi.org/10.1002/wsbm.1184.

80. Arasada R, Schleicher M. Actin cytoskeleton. In: Encyclopedic Reference of Genomics and Proteomics in Molecular Medicine. Berlin, Heidelberg: Springer Berlin Heidelberg; 2006. p. 5-8.

81. Schwartz M. Rho signalling at a glance. J Cell Sci. 2004;117(Pt 23):5457-8. https://doi.org/10.1242/jcs.01582.

82. Eden S, Rohatgi R, Podtelejnikov AV, Mann M, Kirschner MW. Mechanism of regulation of WAVE1-induced actin nucleation by Rac1 and Nck. Nature. 2002;418(6899):790-3. https://doi.org/10.1038/nature00859.

83. Glover NM, Redestig H, Dessimoz C. Homoeologs: what are they and how do we infer them? Trends Plant Sci. 2016;21(7):609-21. https://doi.org/10.1 016/j.tplants.2016.02.005.

84. Bennett AF, Huey RB, John-Alder H. Physiological correlates of natural activity and locomotor capacity in two species of lacertid lizards. J Comp Physiol. 1984;154(2):113-8. https://doi.org/10.1007/BF00684134.

85. Vanhooydonck B, Van Damme R, Aerts P. Speed and stamina trade-off in lacertid lizards. Evolution. 2001;55(5):1040-8. https://doi.org/10.1554/0014-3 820(2001)055[1040:SASTOI]2.0.CO;2.

86. Wilson RS, Niehaus AC, David G, Hunter A, Smith M. Does individual quality mask the detection of performance trade-offs? A test using analyses of human physical performance. J Exp Biol. 2014;217(Pt 4):545-51. https://doi. org/10.1242/jeb.092056.

87. Careau V, Wilson RS. Performance trade-offs and ageing in the 'world's greatest athletes'. Proc Biol Sci. 2017;284(1860)

88. Vincent B, De Bock K, Ramaekers M, Van den Eede E, Van Leemputte M, Hespel P, Thomis MA. ACTN3 (R577X) genotype is associated with fiber type distribution. Physiol Genomics. 2007:32(1):58-63. https://doi.org/10.1152/ physiolgenomics.00173.2007.
89. Kumagai $H$, Tobina T, Ichinoseki-Sekine N, Kakigi R, Tsuzuki T, Zempo H, Shiose K, Yoshimura E, Kumahara H, Ayabe M, Higaki Y, Yamada R, Kobayashi H, Kiyonaga A, Naito H, Tanaka H, Fuku N. Role of selected polymorphisms in determining muscle fiber composition in Japanese men and women. J Appl Physiol. 2018;124(5):1377-84. https://doi.org/10.1152/ja pplphysiol.00953.2017.

90. MacArthur DG, Seto JT, Raftery JM, Quinlan KG, Huttley GA, Hook JW, Lemckert FA, Kee AJ, Edwards MR, Berman Y, et al. Loss of ACTN3 gene function alters mouse muscle metabolism and shows evidence of positive selection in humans. Nat Genet. 2007;39(10):1261-5. https://doi.org/10.1038/ ng2122.

91. Muniesa CA, Gonzalez-Freire M, Santiago C, Lao Jl, Buxens A, Rubio JC, Martin MA, Arenas J, Gomez-Gallego F, Lucia A. World-class performance in lightweight rowing: is it genetically influenced? A comparison with cyclists, runners and non-athletes. Br J Sports Med. 2010;44(12):898-901. https://doi. org/10.1136/bjsm.2008.051680.

92. Talbot J, Maves L. Skeletal muscle fiber type: using insights from muscle developmental biology to dissect targets for susceptibility and resistance to muscle disease. Wiley Interdiscip Rev Dev Biol. 2016;5(4):518-34. https://doi. org/10.1002/wdev.230

93. Xu Q, Modrek B, Lee C. Genome-wide detection of tissue-specific alternative splicing in the human transcriptome. Nucleic Acids Res. 2002;30(17):375466. https://doi.org/10.1093/nar/gkf492.

94. Marden JH, Fitzhugh GH, Wolf MR, Arnold KD, Rowan B. Alternative splicing, muscle calcium sensitivity, and the modulation of dragonfly flight performance. PNAS. 1999;96(26):15304-9. https://doi.org/10.1073/pnas.96.2 6.15304.

95. Wu AR, Neff NF, Kalisky T, Dalerba P, Treutlein B, Rothenberg ME, Mburu FM, Mantalas GL, Sim S, Clarke MF, Quake SR. Quantitative assessment of singlecell RNA-sequencing methods. Nat Methods. 2013;11(1):41-6. https://doi. org/10.1038/nmeth.2694.

96. Dhorne-Pollet S, Thelie A, Pollet N. Validation of novel reference genes for RT-qPCR studies of gene expression in Xenopus tropicalis during embryonic and post-embryonic development. Dev Dyn. 2013;242(6):709-17. https://doi. org/10.1002/dvdy.23972.

97. Bolger AM, Lohse M, Usadel B. Trimmomatic: a flexible trimmer for Illumina sequence data. Bioinformatics. 2014;30(15):2114-20. https://doi.org/10.1093/ bioinformatics/btu170.

98. Grabherr MG, Haas BJ, Yassour M, Levin JZ, Thompson DA, Amit I, Adiconis X, Fan L, Raychowdhury R, Zeng Q, Chen Z, Mauceli E, Hacohen N, Gnirke A, Rhind N, di Palma F, Birren BW, Nusbaum C, Lindblad-Toh K, Friedman N, Regev A. Full-length transcriptome assembly from RNA-Seq data without a reference genome. Nat Biotechnol. 2011;29(7):644-52. https://doi.org/10.103 8/nbt.1883.

99. Seppey M, Manni M, Zdobnov EM. BUSCO: assessing genome assembly and annotation completeness. In: Kollmar M, editor. Gene Prediction: Methods and Protocols. New York, NY: Springer New York; 2019. p. 227-45.

100. Langmead B, Salzberg SL. Fast gapped-read alignment with bowtie 2. Nat Methods. 2012;9(4):357-9. https://doi.org/10.1038/nmeth.1923.

101. Bray NL, Pimentel H, Melsted P, Pachter L. Near-optimal probabilistic RNAseq quantification. Nat Biotechnol. 2016;34(5):525-7. https://doi.org/10.1038/ nbt.3519.

102. Evans BJ, Gansauge MT, Stanley EL, BLS F, CMS C, Ofori-Boateng C, Gvozdik V, Streicher JW, Greenbaum E, Tinsley RC, et al. Xenopus fraseri: Mr. Fraser, where did your frog come from? PLoS One. 2019;14(9):e0220892.

103. Katoh K, Standley DM. MAFFT multiple sequence alignment software version 7: improvements in performance and usability. Mol Biol Evol. 2013; 30(4):772-80. https://doi.org/10.1093/molbev/mst010.

104. Rambaut A: FigTree v1.4.4. A graiphical viewer of phylogenetic trees. [http://tree.bio.ed.ac.uk/software/figtree] 2018.

105. Robinson MD, McCarthy DJ. Smyth GK: edgeR: a bioconductor package for differential expression analysis of digital gene expression data. Bioinformatics. 2009;26(1):139-40. https://doi.org/10.1093/bioinformatics/btp616.

106. Gentleman RC, Carey VJ, Bates DM, Bolstad B, Dettling M, Dudoit S, Ellis B, Gautier L, Ge Y, Gentry J, Hornik K, Hothorn T, Huber W, lacus S, Irizarry R, Leisch F, Li C, Maechler M, Rossini AJ, Sawitzki G, Smith C, Smyth G, Tierney L, Yang JYH, Zhang J. Bioconductor: open software development for computational biology and bioinformatics. Genome Biol. 2004;5(10):R80. https://doi.org/10.1186/gb-2004-5-10-r80.

107. Szklarczyk D, Gable AL, Lyon D, Junge A, Wyder S, Huerta-Cepas J, Simonovic M, Doncheva NT, Morris JH, Bork P, Jensen $L$, Mering C. STRING 
v11: protein-protein association networks with increased coverage, supporting functional discovery in genome-wide experimental datasets. Nucleic Acids Res. 2019;47(D1):D607-13. https:/doi.org/10.1093/nar/gky1131.

108. Barrett T, Wilhite SE, Ledoux P, Evangelista C, Kim IF, Tomashevsky M,

Marshall KA, Phillippy KH, Sherman PM, Holko M, Yefanov A, Lee H, Zhang

N, Robertson CL, Serova N, Davis S, Soboleva A. NCBI GEO: archive for

functional genomics data sets—update. Nucleic Acids Res. 2012;41(D1):

D991-5. https://doi.org/10.1093/nar/gks1193.

\section{Publisher's Note}

Springer Nature remains neutral with regard to jurisdictional claims in published maps and institutional affiliations.

Ready to submit your research? Choose BMC and benefit from:

- fast, convenient online submission

- thorough peer review by experienced researchers in your field

- rapid publication on acceptance

- support for research data, including large and complex data types

- gold Open Access which fosters wider collaboration and increased citations

- maximum visibility for your research: over $100 \mathrm{M}$ website views per year

At $\mathrm{BMC}$, research is always in progress.

Learn more biomedcentral.com/submissions 